\title{
RESEARCH
}

Open Access

\section{Gender differences in attitudes and attributes of people using therapeutic shoes for diabetic foot complications}

\author{
Gustav Jarl ${ }^{1,2^{*}} \mathbb{D}$, John Alnemo ${ }^{3}$, Roy Tranberg $^{4}$ and Lars-Olov Lundqvist ${ }^{2}$
}

\begin{abstract}
Background: Therapeutic shoes can prevent diabetic foot reulcerations but their use is complicated by the fact that shoes have psychological and social meanings, which is believed to put a larger burden on women than men. The aim was to compare attitudes and attributes of women and men using therapeutic shoes for diabetic foot complications.
\end{abstract}

Methods: A questionnaire was posted to 1230 people with diabetes who had been fitted with therapeutic shoes. Women's and men's answers were compared using t-tests, Mann-Whitney $U$ tests and chi-square tests with Fischer's exact tests. P-values $<0.05$ were considered statistically significant.

Results: Questionnaires from 443 (36.0\%) respondents (294 men, 149 women, mean age 69.2 years) were analyzed. More men than women $(p<0.05)$ had paid employment $(20.4 \%$ vs $9.4 \%)$, had someone who reminded them to wear their therapeutic shoes (27.6\% vs $10.0 \%)$, and had a history of foot ulcers (62.9\% vs $46.3 \%)$ or minor amputation (17.7\% vs 6.7\%). More women than men received disability pension (18.8\% vs $10.2 \%)$. Women reported worse general health, lower internal locus of control regarding ulcer prevention, and more negative attitudes to the appearance and price of therapeutic shoes and how they felt about wearing them in public. Other comparisons were non-significant: other shoe attributes, education, diabetes type, current foot ulcers, major amputations, satisfaction with shoe services, understanding of neuropathy as a risk factor, locus of control regarding ulcer healing, belief in the shoes' efficacy to prevent and heal ulcers, worries about ulcer healing and new ulcerations, self-efficacy, depression, shoe use/adherence, paying a fee for therapeutic shoes, and social support.

Conclusions: Men had worse foot complications. Women had worse general health, lower internal locus of control regarding ulcer prevention, and more negative attitudes toward therapeutic shoes. Clinicians should pay more attention to their female patients' concerns. Future research and development should focus on improving the weight and appearance of therapeutic shoes, particularly for women. Research is also needed on how to facilitate the adaption and reevaluation process where patients change from viewing shoes purely as items of clothing to also viewing them as medical interventions.

Keywords: Diabetes mellitus, Diabetic foot, Diabetes complications, Shoes, Patient compliance, Treatment adherence and compliance

\footnotetext{
* Correspondence: gustav.jarl@regionorebrolan.se

'Department of Prosthetics and Orthotics, Faculty of Medicine and Health,

Örebro University, SE 70182 Örebro, Sweden

${ }^{2}$ University Health Care Research Center, Faculty of Medicine and Health,

Örebro University, SE 70182 Örebro, Sweden

Full list of author information is available at the end of the article
}

(c) The Author(s). 2019 Open Access This article is distributed under the terms of the Creative Commons Attribution 4.0 International License (http://creativecommons.org/licenses/by/4.0/), which permits unrestricted use, distribution, and reproduction in any medium, provided you give appropriate credit to the original author(s) and the source, provide a link to the Creative Commons license, and indicate if changes were made. The Creative Commons Public Domain Dedication waiver (http://creativecommons.org/publicdomain/zero/1.0/) applies to the data made available in this article, unless otherwise stated. 


\section{Background}

Diabetic foot ulcers are a common and devastating complication of diabetes. The lifetime incidence of foot ulcers has been estimated to be between 19 and 34\%, and these ulcers are associated with significant morbidity, mortality, and risk of lower extremity amputations [1]. Although most ulcers heal, recurrence rates are high: approximately $40 \%$ of foot ulcers recur within 1 year of healing, and $60 \%$ within 3 years [1]. A systematic review [2] found that therapeutic shoes are beneficial in preventing the recurrence of plantar foot ulcers and, consequently, they are recommended in international guidelines [3]. Despite this, many patients use their therapeutic shoes less than recommended [4], which reduces the protective effect [5]. At first glance, the use of therapeutic shoes may seem trivial: if offloading is effective and adherence high, fewer foot ulcers will recur. However, using therapeutic shoes as medical interventions is complicated by the fact that shoes have psychological and cultural meanings that transcend their functionality [6]. The transformation from the everyday perspective of shoes as items of clothing to a medical perspective of shoes as medical interventions is challenging and can take considerable time and effort [7]. Qualitative studies on people with diabetes have suggested that women in particular dislike wearing therapeutic shoes, which they view as big, ugly, and unfeminine, affecting their self-image [7-9]. However, most quantitative studies on gender differences in people with diabetic foot complications have more narrowly focused on adherence to wearing therapeutic shoes, and a review from 2016 [10] found no gender difference in adherence in the five included studies [4, 11-14]. One quantitative study [15] investigated gender differences in attitudes toward therapeutic shoes and found that, although fewer of the men were given a choice of shoe style, they were still more satisfied with the shoes than the women, suggesting that future quantitative studies should investigate gender aspects of therapeutic shoe use from a wider perspective. Thus, the aim of this study was to compare attitudes and attributes of women and men using therapeutic shoes for diabetic foot complications.

\section{Methods}

\section{Study design and setting}

The study design was cross-sectional and observational, using a postal survey that was sent to patients at two prosthetic and orthotic clinics in two counties in Sweden.

\section{Construction and pilot test of questionnaire}

A questionnaire was constructed based on a literature review of factors that affect adherence to wearing therapeutic shoes among people with diabetes [10]. Factors from the health belief model [16] were also included in the questionnaire. The questions covered demographics, diabetes and foot complications, satisfaction with services, understanding of sensory neuropathy as a risk factor for foot ulcers, internal locus of control, belief in efficacy of therapeutic shoes, worries about prevention and healing of foot ulcers, self-efficacy, general health, depression, attitudes to therapeutic and conventional shoes, shoe use, reminders to use therapeutic shoes, and social support. Several of the items were copied or adapted from existing questionnaires [17-25].

A pilot test of the questionnaire was conducted on five individuals (two women, three men, median age 67 years, range $48-80$ years) with diabetes and previous or current foot ulcers. They answered the questionnaire and were later interviewed by telephone by the first author about their understanding of the questions and response alternatives. Only minor adjustments to the questionnaire were needed as a result of the interviews: one question was reworded and a new response alternative was added to another question.

\section{Participants and procedure}

The inclusion criteria were having diabetes, being at least 18 years of age (on January 1, 2016), having been prescribed therapeutic shoes at some point in time, and having visited one of two prosthetic and orthotic clinics in the period January to December 2016. The exclusion criterion was bilateral major amputation. The questionnaire and study information were sent by post to the 1230 people fulfilling these criteria and still living in May and June 2017. A reminder was sent 1 month later to those who had not returned the questionnaire.

\section{Statistical analyses}

Women's and men's answers were compared using twosided $t$-tests, Mann-Whitney $U$ tests, and chi-square tests with Fischer's exact tests. P-values less than 0.05 were considered statically significant. IBM SPSS, version 22, was used for the statistical analyses.

\section{Results}

Of the 1230 people who received the questionnaire, 469 returned valid answers and, of those, 26 were excluded because the respondents stated that they did not own any therapeutic shoes. The remaining 443 questionnaires were included in the analysis, giving a response rate of $36.0 \%$. The majority of the respondents were retired men, with type 2 diabetes (Table 1). Comparisons of demographic and disease-related variables revealed that more men than women were in paid employment and had a history of foot ulcers or minor amputations. More women than men reported that they received disability pension. There were no significant gender differences in age, education, diabetes type, current foot ulcers, or major amputations. 
Table 1 Demographic characteristics of participants

\begin{tabular}{|c|c|c|c|c|c|}
\hline & & All $(n=443)$ & Men $(n=294)$ & Women $(n=149)$ & $P$-value ${ }^{a}$ \\
\hline Age, mean (sd) & & $69.2(10.6)$ & $69.1(10.3)$ & $69.4(11.4)$ & 0.794 \\
\hline \multirow[t]{5}{*}{ Education, n (\%) } & Incomplete elementary schooling & $11(2.5)$ & $8(2.7)$ & $3(2.0)$ & $0.758^{\mathrm{b}}$ \\
\hline & Elementary school & $150(33.9)$ & $103(35.0)$ & $47(31.5)$ & 0.502 \\
\hline & Upper secondary school & $154(34.8)$ & $104(35.4)$ & 50 (33.6) & 0.756 \\
\hline & College/university & $110(24.8)$ & $68(23.1)$ & $42(28.2)$ & 0.218 \\
\hline & Missing & $18(4.1)$ & $11(3.7)$ & $7(4.7)$ & \\
\hline \multirow[t]{7}{*}{ Occupation, n (\%) } & Retired & $306(69.1)$ & $206(70.1)$ & $100(67.1)$ & 0.548 \\
\hline & Paid employment & $74(16.7)$ & $60(20.4)$ & $14(9.4)$ & 0.003 \\
\hline & Unemployed & $12(2.7)$ & $7(2.4)$ & $5(3.4)$ & $0.547^{\mathrm{b}}$ \\
\hline & Student & $3(0.7)$ & $1(0.3)$ & $2(1.3)$ & $0.262^{\mathrm{b}}$ \\
\hline & Disability pension & $58(13.1)$ & $30(10.2)$ & $28(18.8)$ & 0.011 \\
\hline & Sick leave & $25(5.6)$ & $16(5.4)$ & $9(6.0)$ & 0.790 \\
\hline & Missing & $8(1.8)$ & $5(1.7)$ & $3(2.0)$ & \\
\hline \multirow[t]{4}{*}{ Diabetes type, n (\%) } & Type 1 & $120(27.1)$ & $71(24.1)$ & $49(32.9)$ & 0.051 \\
\hline & Type 2 & $320(72.2)$ & $220(74.8)$ & $100(67.1)$ & 0.087 \\
\hline & Other type & $3(0.7)$ & $3(1.0)$ & 0 & $0.554^{\mathrm{b}}$ \\
\hline & Missing & 0 & 0 & 0 & \\
\hline \multirow[t]{3}{*}{ Current ulcer, n (\%) } & Yes & $135(30.5)$ & $89(30.3)$ & $46(30.9)$ & 0.897 \\
\hline & No & $305(68.8)$ & $203(69.0)$ & $102(68.5)$ & \\
\hline & Missing & $3(0.7)$ & $2(0.7)$ & $1(0.7)$ & \\
\hline \multirow[t]{3}{*}{ Previous ulcer, n (\%) } & Yes & $254(57.3)$ & $185(62.9)$ & $69(46.3)$ & 0.001 \\
\hline & No & $175(39.5)$ & $100(34.0)$ & $75(50.3)$ & \\
\hline & Missing & $14(3.2)$ & $9(3.1)$ & $5(3.4)$ & \\
\hline \multirow[t]{3}{*}{ Minor amputation, n (\%) } & Yes & $62(14.0)$ & $52(17.7)$ & $10(6.7)$ & 0.002 \\
\hline & No & $370(83.5)$ & $237(80.6)$ & $133(89.3)$ & \\
\hline & Missing & $11(2.5)$ & $5(1.7)$ & $6(4.0)$ & \\
\hline \multirow[t]{3}{*}{ Major amputation, n (\%) } & Yes & $20(4.5)$ & $17(5.8)$ & $3(2.0)$ & 0.074 \\
\hline & No & $414(93.5)$ & $272(92.5)$ & $142(95.3)$ & \\
\hline & Missing & $9(2.0)$ & $5(1.7)$ & $4(2.7)$ & \\
\hline
\end{tabular}

${ }^{a} \mathrm{~A}$ two-sided $t$-test was used to compare the age of men and women. Two-sided chi-square tests were used for all other comparisons. For variables with two response categories, a single chi-square test was used. For variables with three or more response categories, a separate chi-square test was used for each response category. $P$-values less than 0.05 are written in boldface

'Two-sided Fischer's exact test was used because at least one cell had an expected cell count below 5

${ }^{\mathrm{C}}$ The percentages add up to more than $100 \%$ because more than one alternative could be chosen

Both women and men were satisfied with the shoe services at the prosthetic and orthotic clinic, agreed that sensory neuropathy increases the risk of foot ulcers, expressed internal locus of control for prevention and healing of foot ulcers, agreed that using therapeutic shoes can improve prevention and healing, were somewhat worried about prevention and healing, and expressed self-efficacy about using therapeutic shoes (Table 2). Compared to men, women reported worse general health and lower internal locus of control regarding prevention of ulcerations.

In the sample as a whole, therapeutic shoes were preferred to conventional shoes when it came to the shoes' effect on preventing and healing foot ulcers, price, fit, difficulties putting them on and taking them off, pain when standing or walking, difficulties walking in them, and using them in daily activities (Table 3 ). On the other hand, they preferred conventional shoes to therapeutic shoes when it came to the appearance and weight of the shoes. When comparing women and men, women held more negative attitudes to the appearance and price of therapeutic shoes, and preferred to wear conventional shoes in public. More men than women reported that clinic staff and people close to them reminded them to use their therapeutic shoes (Table 4). There were no gender differences in time spent wearing therapeutic and 
Table 2 Summary of responses to questions about attitudes and beliefs (abbreviated item texts), mean values (SD)

\begin{tabular}{|c|c|c|c|c|}
\hline & All & Men & Women & $P$-value ${ }^{a}$ \\
\hline 1. The staff were responsive to my concerns and questions & $1.5(0.6)$ & $1.5(0.6)$ & $1.6(0.6)$ & 0.146 \\
\hline 2. I was a partner in the decision-making with clinic staff & $1.6(0.6)$ & $1.6(0.6)$ & $1.6(0.6)$ & 0.740 \\
\hline 3. I am satisfied with the follow-up of my therapeutic shoes & $2.2(1.2)$ & $2.2(1.2)$ & $2.2(1.2)$ & 0.809 \\
\hline 4. Lost/reduced sensation in your feet increases the risk of foot ulcerations & $2.1(1.2)$ & $2.1(1.2)$ & $2.1(1.3)$ & 0.988 \\
\hline 5. What you do yourself is the main thing that affects whether your foot ulcer heals & $2.1(0.9)$ & $2.1(0.9)$ & $2.1(0.9)$ & 0.860 \\
\hline 6. What you do yourself is the main thing that affects whether you develop new foot ulcers & $2.3(1.1)$ & $2.2(1.1)$ & $2.5(1.2)$ & 0.048 \\
\hline 7. Probability of ulcer healing within 3 months if I always use therapeutic shoes & $2.1(0.9)$ & $2.1(0.9)$ & $2.3(0.9)$ & 0.155 \\
\hline 8. Probability of ulcer healing within 3 months if I never use therapeutic shoes & $2.8(1.0)$ & $2.9(1.0)$ & $2.8(1.0)$ & 0.671 \\
\hline 9. Probability of new ulceration within 12 months if I always use therapeutic shoes & $3.0(0.8)$ & $3.0(0.8)$ & $2.9(0.9)$ & 0.439 \\
\hline 10. Probability of new ulceration within 12 months if I never use therapeutic shoes & $2.2(1.0)$ & $2.3(1.0)$ & $2.1(1.0)$ & 0.101 \\
\hline 11. Worried that my foot ulcer(s) will never heal & $2.7(1.2)$ & $2.8(1.2)$ & $2.6(1.3)$ & 0.271 \\
\hline 12. Worried about getting new foot ulcers in the future & $3.0(1.3)$ & $3.0(1.3)$ & $3.1(1.4)$ & 0.641 \\
\hline 13. Confident I would always use therapeutic shoes if I decided to do so & $1.9(1.0)$ & $1.9(0.9)$ & $2.0(1.2)$ & 0.611 \\
\hline 14. General health & $3.4(1.0)$ & $3.4(1.0)$ & $3.6(0.9)$ & 0.014 \\
\hline 15. Feeling down, depressed, or hopeless & $3.2(1.0)$ & $3.3(1.0)$ & $3.2(1.0)$ & 0.297 \\
\hline
\end{tabular}

${ }^{a}$ Two-sided Mann-Whitney $\mathrm{U}$ test. The $p$-values less than 0.05 are written in boldface. Rating scales, items 1-3: $1=$ strongly agree to $3=$ disagree; items 4-6: $1=$ strongly agree to $5=$ strongly disagree; items 7-10: $1=$ Highly probable to $4=$ highly improbable; items $11-12: 1=$ Very much to $5=$ Not at all; item $13: 1=$ Very certain to $4=$ Very uncertain; item 14: $1=$ Excellent to $5=$ Bad, item 15: $1=$ Almost every day to $4=$ Not at all

conventional shoes, paying a fee for therapeutic shoes, or the availability of social support from a relative or friend.

\section{Discussion}

The aim of this study was to compare attitudes and attributes of women and men using therapeutic shoes. Like many other studies on people with diabetic foot complications, the majority of our respondents were men. Somewhat surprisingly, men reported more severe foot complications than women, but more men than women were in paid employment and fewer were on disability pension. This might be related to the fact that women had worse general health, but the cross-sectional and observational study design precludes any inferences about the casual relationships. Men to a greater extent reported that clinic staff and people close to them reminded them to wear their therapeutic shoes. This is in accordance with our clinical experience that the wives of many male patients are actively involved in the care of their husbands, while the husbands of female patients may not be involved to the same extent. More troubling is the fact that the female patients were reminded less by the clinic staff, which suggests that female and male patients are to some extent treated differently.

Table 3 Preferences for therapeutic and conventional shoes, mean values (SD)

\begin{tabular}{|c|c|c|c|c|}
\hline & All & Men & Women & $P$-value \\
\hline Effect on ulcer healing & $1.8(0.8)$ & $1.8(0.8)$ & $1.9(0.9)$ & 0.357 \\
\hline Effect on reducing risk of new ulcers & $1.8(0.8)$ & $1.8(0.8)$ & $1.8(0.8)$ & 0.588 \\
\hline Difficulties walking in the shoes & $2.3(1.1)$ & $2.3(1.1)$ & $2.3(1.2)$ & 0.958 \\
\hline Appearance & $3.4(1.2)$ & $3.3(1.2)$ & $3.6(1.2)$ & 0.006 \\
\hline Weight & $3.3(1.1)$ & $3.3(1.1)$ & $3.3(1.1)$ & 0.563 \\
\hline Price & $2.7(1.1)$ & $2.5(1.1)$ & $2.9(1.1)$ & 0.003 \\
\hline Pain when standing and walking & $2.1(1.0)$ & $2.1(0.9)$ & $2.2(1.1)$ & 0.216 \\
\hline Difficulties putting on and taking off the shoes & $2.6(1.0)$ & $2.5(1.0)$ & $2.7(1.0)$ & 0.063 \\
\hline Ease of use in everyday activities, e.g. in your work & $2.3(1.1)$ & $2.3(1.1)$ & $2.3(1.1)$ & 0.982 \\
\hline Feeling inclined to wear the shoes in public & $3.0(1.1)$ & $2.9(1.1)$ & $3.2(1.1)$ & 0.024 \\
\hline Fit of the shoes & $2.2(1.1)$ & $2.2(1.0)$ & $2.3(1.1)$ & 0.517 \\
\hline
\end{tabular}

${ }^{a}$ Two-sided Mann-Whitney $U$ test. $P$-values less than 0.05 are written in boldface. Rating scale: $1=$ therapeutic shoes are much better, $2=$ therapeutic shoes are better, $3=$ no difference, $4=$ conventional shoes are better, $5=$ conventional shoes are much better 
Table 4 Shoe use, fees, and social support

\begin{tabular}{|c|c|c|c|c|}
\hline & All $(n=443)$ & Men $(n=294)$ & Women $(n=149)$ & $P$-value ${ }^{a}$ \\
\hline Weekly use of therapeutic shoes, days/week (SD) & $5.9(2.0)$ & $5.9(2.0)$ & $5.8(2.0)$ & 0.691 \\
\hline Weekly use of conventional shoes, days/week (SD) & $2.2(2.8)$ & $2.0(2.7)$ & $2.4(2.9)$ & 0.198 \\
\hline Daily use of therapeutic shoes, hours/day (SD) & $8.5(4.7)$ & $8.3(4.6)$ & $8.9(4.9)$ & 0.214 \\
\hline Daily use of conventional shoes, hours/day (SD) & $3.4(3.3)$ & $3.4(3.4)$ & $3.4(3.2)$ & 0.991 \\
\hline Percentage of waking day in therapeutic shoes, mean (SD) & $50.3(32.8)$ & $49.4(32.0)$ & $52.2(34.5)$ & 0.395 \\
\hline Percentage of waking day in conventional shoes, mean (SD) & $12.1(21.1)$ & $11.5(21.1)$ & $13.3(21.3)$ & 0.419 \\
\hline \multicolumn{5}{|l|}{ Use of therapeutic shoes at least $60 \%$ of waking day, $n(\%)$} \\
\hline Yes & $169(38.1)$ & $110(37.4)$ & $59(39.6)$ & \multirow[t]{3}{*}{0.520} \\
\hline No & $260(58.7)$ & $177(60.2)$ & $83(55.7)$ & \\
\hline Missing & $14(3.2)$ & $7(2.4)$ & $7(4.7)$ & \\
\hline \multicolumn{5}{|l|}{ Did you pay a fee for your current therapeutic shoes? n (\%) } \\
\hline Yes & $335(75.6)$ & $218(74.1)$ & $117(78.5)$ & \multirow[t]{3}{*}{0.420} \\
\hline No & $92(20.8)$ & $64(21.8)$ & $28(18.8)$ & \\
\hline Missing & $16(3.6)$ & $12(4.1)$ & $4(2.7)$ & \\
\hline \multicolumn{5}{|l|}{$\begin{array}{l}\text { Does someone usually remind you to use your therapeutic } \\
\text { shoes?, n }(\%)^{b}\end{array}$} \\
\hline Yes, clinic staff & $58(13.1)$ & $47(16.0)$ & $11(7.4)$ & 0.014 \\
\hline Yes, people close to me & $50(11.3)$ & $44(15.0)$ & $6(4.0)$ & 0.001 \\
\hline No & $331(74.7)$ & $205(69.7)$ & $126(84.6)$ & \multirow[t]{2}{*}{$<0.001$} \\
\hline Missing & $16(3.6)$ & $8(2.7)$ & $8(5.4)$ & \\
\hline \multicolumn{5}{|l|}{$\begin{array}{l}\text { Is there someone close to you who supports you with } \\
\text { your foot problems? n (\%) }\end{array}$} \\
\hline Yes & $262(59.1)$ & $178(60.5)$ & $84(56.4)$ & \multirow[t]{3}{*}{0.363} \\
\hline No & 168 (37.9) & $107(36.4)$ & $61(40.9)$ & \\
\hline Missing & $13(2.9)$ & $9(3.1)$ & $4(2.7)$ & \\
\hline
\end{tabular}

${ }^{a}$ Two-sided t-tests were used for comparisons of weekly and daily shoe use. For variables with two response categories, a single chi-square test was used. For variables with three or more response categories, a separate chi-square test was used for each response category. $P$-values less than 0.05 are written in boldface. Adherence was estimated with two questions adapted from the Questionnaire for persons with a transfemoral amputation [19]

${ }^{\mathrm{b}}$ The percentages add up to more than $100 \%$ because some respondents were reminded by both clinic staff and people close to them (e.g. a relative or friend)

Both women and men preferred therapeutic shoes when it came to their functional aspects. This is in accordance with other studies, in which users of therapeutic shoes have generally been satisfied with the fit $[13,15]$ and comfort $[4,12,15]$ and have felt that therapeutic shoes were of benefit to their feet [15]. In contrast, both women and men preferred the appearance and weight of conventional shoes, and the preference for their appearance was more pronounced among the women. The higher dissatisfaction among women with the appearance of therapeutic shoes and their disinclination to wear them in public may be related to the fact that fashionable shoes for women are often less functional than fashionable shoes for men; gender differences in shoe styles are large [26] although gender differences in foot shape are relatively small when adjusted for foot length [27]. Many studies have reported low satisfaction with and complaints about the appearance [4, 12, 13, 28] and weight $[12,28]$ of therapeutic shoes, but usually without comparing women's answers with men's, which may have obscured gender differences like the ones that we found. Still, the more negative attitudes of women toward the appearance of therapeutic shoes and how they felt about wearing them in public are in accordance with qualitative studies, in which women have stressed how unattractive and unfeminine therapeutic shoes are and how this impacts their self-esteem and participation in social life $[7-9,29]$. In our study, women had less positive opinions about the price they paid for their therapeutic shoes, although the proportion of women and men that had paid a fee for their shoes did not differ. The explanation may be that women were more dissatisfied with other aspects of their therapeutic shoes, making them feel that the therapeutic shoes were not worth the fee paid for them. It is less clear why women reported lower internal locus of control regarding prevention of ulcerations, especially as there was no gender difference in locus of control regarding ulcer healing. 
Adherence to wearing therapeutic shoes have been investigated in several studies but comparisons with other studies are difficult because they often define and measure adherence in different ways [30]. However, two studies [12, 28] using a similar methodology to the current study, that is, questionnaires asking participants to estimate how much they wore their therapeutic shoes, report that $42 \%$ of the participants wore their therapeutic shoes for at least $60 \%$ of their waking day. This is similar to our study, where $38.1 \%$ wore their therapeutic shoes for at least $60 \%$ of their waking day. We found no association between gender and adherence, which is consistent with findings from previous studies $[4,11-14]$ and is interesting considering that the female respondents had more negative opinions about their therapeutic shoes. This suggests that adherence may be influenced by multiple factors [10], and will be investigated with multivariate analysis in future studies on this dataset.

Although we found some differences between women and men, we should not forget that most comparisons were non-significant. This could be related to the fact that the study was conducted in Sweden, which is ranked among the countries with the smallest gender gaps in the world [31]; the observed gender similarities may therefore not be transferable to countries with larger gender gaps. With this is mind, the observed results point to some implications for clinical practice and research. First, developments in shoe design and materials are needed to reduce the weight of therapeutic shoes. Second, the issue of the appearance of therapeutic shoes needs more attention, in particular for women's shoes. There may be a need to make certain models of therapeutic shoes more feminine, without compromising their fit and function. Female patients are often in the minority, and it is important for clinicians to remind them to wear their therapeutic shoes and to be aware that their preferences may differ from those of the male patients. Also, clinicians and researchers need to pay more attention to how to facilitate the reevaluation process, in which patients change their views and priorities from only viewing shoes as items of clothing to also viewing them as medical interventions. As a result, they give weight not only to esthetic attributes but also to functional benefits such as preventing foot ulcerations.

\section{Limitations}

This study has some limitations. First, the study sample consisted of patients who had received therapeutic shoes and thus patients who refused therapeutic shoes in the first place were not included. Thus, the study may have underestimated the negative attitudes toward therapeutic shoes. Second, the survey respondents were patients from two prosthetics and orthotics clinics in Sweden, and these patients may not be representative of all patients with diabetic foot complications. Third, the response rate was low and we cannot know whether the results of comparing women and men would be the same if all people surveyed had answered the questionnaire.

\section{Conclusions}

Our major findings were that men had more severe foot complications than women but women had worse general health, lower internal locus of control regarding ulcer prevention, and more negative attitudes toward therapeutic shoes. Clinicians need to pay more attention to their female patients' concerns. Future research and development should focus on improving the weight and appearance of therapeutic shoes, in particular shoes for women. Also, more research is needed on how to facilitate the adaption and reevaluation process in which patients change from viewing shoes purely as items of clothing to also viewing them as medical interventions.

\section{Acknowledgements}

Not applicable.

\section{Funding}

This study was supported by Region Örebro County, Sweden. The funder had no influence on study design, collection, analysis, and interpretation of the data, writing of the manuscript or the decision to submit it for publication.

\section{Availability of data and materials}

The dataset analyzed during the current study is not publicly available for reasons of confidentiality and because the authors plan to publish additional analyses on this dataset.

\section{Authors' contributions}

All authors planned the study. GJ and JA collected the data. GJ analyzed the data and wrote the manuscript. All authors contributed to discussions of the text and approved the final version of the manuscript.

Ethics approval and consent to participate

The study was approved by the Regional Ethics Committee Review Board of Uppsala, reference number 2016/528.

\section{Consent for publication}

Not applicable.

\section{Competing interests}

GJ is a consultant for Novo Nordisk but does not consider this to be a conflict of interest in this work. RT, JA, and LOL declare that they have no competing interests.

\section{Publisher's Note}

Springer Nature remains neutral with regard to jurisdictional claims in published maps and institutional affiliations.

\section{Author details}

${ }^{1}$ Department of Prosthetics and Orthotics, Faculty of Medicine and Health, Örebro University, SE 70182 Örebro, Sweden. ${ }^{2}$ University Health Care Research Center, Faculty of Medicine and Health, Örebro University, SE 70182 Örebro, Sweden. ${ }^{3}$ Department of Prosthetics and Orthotics, Sahlgrenska University Hospital, Gothenburg, Sweden. ${ }^{4}$ Department of Orthopaedics, Institute of Clinical Sciences, the Sahlgrenska Academy at University of Gothenburg, Gothenburg, Sweden. 
Received: 17 January 2019 Accepted: 4 March 2019

Published online: 29 March 2019

\section{References}

1. Armstrong DG, Boulton AJM, Bus SA. Diabetic foot ulcers and their recurrence. N Engl J Med. 2017;376:2367-75.

2. Van Netten JJ, Price PE, Lavery LA, Monteiro-Soares M, Rasmussen A, Jubiz Y, Bus SA. Prevention of foot ulcers in the at-risk patient with diabetes: a systematic review. Diabetes Metab Res Rev. 2016;32(Suppl 1):84-98.

3. Bus SA, Van Netten JJ, Lavery LA, Monteiro-Soares M, Rasmussen A, Jubiz Y, Price PE. IWGDF quidance on the prevention of foot ulcers in at-risk patients with diabetes. Diabetes Metab Res Rev. 2016;32:16-24.

4. Waaijman R, Keukenkamp R, de Haart M, Polomski WP, Nollet F, Bus SA. Adherence to wearing prescription custom-made footwear in patients with diabetes at high risk for plantar foot ulceration. Diabetes Care. 2013;36:1613-8.

5. Waaijman $R$, de Haart M, Arts ML, Wever D, Verlouw AJ, Nollet F, Bus SA. Risk factors for plantar foot ulcer recurrence in neuropathic diabetic patients. Diabetes Care. 2014;37:1697-705.

6. Hockey J, Dilley R, Robinson V, Sherlock A. Worn shoes: identity, memory and footwear. Sociol Res Online. 2013;18:1-14.

7. Paton J, Roberts A, Glasser S, Collings R, Marsden J. "All I wanted was a pair of shoes": a qualitative case study. Diabetic Foot J. 2014;17:100-6.

8. Paton JS, Roberts A, Bruce GK, Marsden J. Patients' experience of therapeutic footwear whilst living at risk of neuropathic diabetic foot ulceration: an interpretative phenomenological analysis (IPA). J Foot Ankle Res. 2014;7:16

9. Beattie AM, Campbell R, Vedhara K. What ever I do it's a lost cause.' the emotional and behavioural experiences of individuals who are ulcer free living with the threat of developing further diabetic foot ulcers: a qualitative interview study. Health Expect. 2014;17:429-39.

10. Jarl G, Lundqvist L-O. Adherence to wearing therapeutic shoes among people with diabetes: a systematic review and reflections. Patient Prefer Adherence. 2016;10:1521-8.

11. Chantelau E, Haage P. An audit of cushioned diabetic footwear: relation to patient compliance. Diabet Med. 1994;11:114-6.

12. Arts ML, de Haart M, Bus SA, Bakker JP, Hacking HG, Nollet F. Perceived usability and use of custom-made footwear in diabetic patients at high risk for foot ulceration. J Rehabil Med. 2014;46:357-62.

13. Breuer U. Diabetic patient's compliance with bespoke footwear after healing of neuropathic foot ulcers. Diabet Metab. 1994;20:415-9.

14. Churchman N. A retrospective audit of footwear use by high-risk individuals in north Derbyshire. Diabetic Foot J. 2008;11:10-8.

15. Knowles EA, Boulton AJ. Do people with diabetes wear their prescribed footwear? Diabet Med. 1996:13:1064-8.

16. Rosenstock IM. Historical origins of the health belief model. Health Educ Monogr. 1974;2:328-35.

17. Bann CM, Fehnel SE, Gagnon DD. Development and validation of the diabetic foot ulcer scale-short form (DFS-SF). Pharmacoeconomics. 2003; 21:1277-90

18. Jarl GM, Heinemann AW, Norling Hermansson LM. Validity evidence for a modified version of the orthotics and prosthetics users' survey. Disabil Rehabil Assist Technol. 2012;7:469-78.

19. Hagberg K, Brånemark R, Hägg O. Questionnaire for persons with a Transfemoral amputation (Q-TFA): initial validity and reliability of a new outcome measure. J Rehabil Res Dev. 2004:41:695-706.

20. Wallston KA, Stein MJ, Smith CA. Form C of the MHLC scales: a conditionspecific measure of locus of control. J Pers Assess. 1994;63:534-53.

21. Samuelsson K, Wressle E. User satisfaction with mobility assistive devices: an important element in the rehabilitation process. Disabil Rehabil. 2008;30:551-8.

22. Ekback $M$, Benzein $E$, Lindberg $M$, Arestedt $K$. The Swedish version of the multidimensional scale of perceived social support (MSPSS)--a psychometric evaluation study in women with hirsutism and nursing students. Health Qual Life Outcomes. 2013;11:168.

23. Kroenke K, Spitzer RL, Williams JB. The PHQ-9: validity of a brief depression severity measure. J Gen Intern Med. 2001;16:606-13.

24. Vileikyte L, Gonzalez JS, Leventhal H, Peyrot MF, Rubin RR, Garrow A, Ulbrecht JS, Cavanagh PR, Boulton AJ. Patient interpretation of neuropathy (PIN) questionnaire: an instrument for assessment of cognitive and emotional factors associated with foot self-care. Diabetes Care. 2006;29:2617-24.
25. Sullivan M, Karlsson J, Ware JE, Jr.: The Swedish SF-36 health survey--I. Evaluation of data quality, scaling assumptions, reliability and construct validity across general populations in Sweden. Soc Sci Med 1995, 41:1349-1358.

26. Barwick AL, van Netten JJ, Reed LF, Lazzarini PA. Independent factors associated with wearing different types of outdoor footwear in a representative inpatient population: a cross-sectional study. J Foot Ankle Res. 2018;11:19.

27. Wunderlich RE, Cavanagh PR. Gender differences in adult foot shape: implications for shoe design. Med Sci Sports Exerc. 2001;33:605-11.

28. Macfarlane DJ, Jensen JL. Factors in diabetic footwear compliance. J Am Podiatr Med Assoc. 2003:93:485-91.

29. Williams AE, Nester CJ, Ravey MI, Kottink A, Klapsing M-G. Women's experiences of wearing therapeutic footwear in three European countries. J Foot Ankle Res. 2010;3:23.

30. Jarl G. Methodological considerations of investigating adherence to using offloading devices among people with diabetes. Patient Prefer Adherence. 2018;12:1767-75.

31. World Economic Forum. The global gender gap report. Geneva; 2017.
Ready to submit your research? Choose BMC and benefit from:

- fast, convenient online submission

- thorough peer review by experienced researchers in your field

- rapid publication on acceptance

- support for research data, including large and complex data types

- gold Open Access which fosters wider collaboration and increased citations

- maximum visibility for your research: over $100 \mathrm{M}$ website views per year

At $\mathrm{BMC}$, research is always in progress.

Learn more biomedcentral.com/submissions 